\title{
Referencia del paciente con Enfermedad Renal Crónica para trasplante: ¿Quién debe completar el protocolo?
} Sistema de referencia y contrarreferencia

\author{
Reference of the patient with Chronic Renal Disease to the \\ nephrologist for transplantation: who should complete the study? \\ Referral and counter-referral system
}

\author{
Josefina Alberú-Gómez, ${ }^{*}$ Jacobo Kelber Berger ${ }^{\ddagger}$ \\ * Catedrática. Escuela de Medicina. Instituto Tecnológico de Monterrey, Campus México. \\ ‡ Nefrólogo, Centro Médico ABC.
}

Todos los pacientes con enfermedad renal crónica (ERC) $($ KDIGO G4-G5 = TFGe $<30 \mathrm{~mL} / \mathrm{min} / 1.73$ $\mathrm{m}^{2}$ ) de quienes se espera llegarán a ERC terminal (ERCT), deberán ser referidos a nefrología y ser considerados para trasplante renal, independientemente del estatus socioeconómico, la edad, el sexo o etnicidad.

a) La evaluación nefrológica con fines de trasplante deberá, idealmente, iniciar de seis a 12 meses antes del momento en el que se anticipe el comienzo de diálisis para facilitar la identificación/estudio de donantes vivos y planificar un posible trasplante anticipado:

- Pacientes adultos no diabéticos: iniciar evaluación con TFGe $\leq 20 \mathrm{~mL} / \mathrm{min} / 1.73 \mathrm{~m}^{2}$.

- Pacientes adultos diabéticos: iniciar evaluación con TFGe $\leq 25 \mathrm{~mL} / \mathrm{min} / 1.73 \mathrm{~m}^{2}$.

- Pacientes pediátricos: iniciar evaluación con TFGe $\leq 25 \mathrm{~mL} / \mathrm{min} / 1.73 \mathrm{~m}^{2}$.

b) El trasplante renal de donante vivo anticipado a diálisis se debe realizar idealmente en:

- Pacientes adultos con TFGe $\leq 15 \mathrm{~mL} /$ $\mathrm{min} / 1.73 \mathrm{~m}^{2}$.
- Pacientes pediátricos con TFGe $\leq 20 \mathrm{~mL} /$ $\mathrm{min} / 1.73 \mathrm{~m}^{2}$.

c) Referir candidatos a trasplante renal (CTR) que ya se encuentren en diálisis, médicamente estables y cuya falla de función renal es considerada irreversible.

1. Patologías o condiciones ante las cuales no debe referirse pacientes para evaluación a trasplante renal:

a) Alteración psiquiátrica activa o utilización de alcohol o drogas psicoactivas que interfieren con el proceso de toma de decisiones o coloque al individuo en un riesgo postrasplante mayor al aceptable a juicio del programa de trasplante. Una historia de adicción y/o uso de alcohol o de drogas psicoactivas en el pasado no necesariamente constituye una contraindicación para ser evaluado como CTR y tendrá que ser evaluado ese caso en particular por psiquiatría y la decisión con respecto a su candidatura deberá ser tomada por el Comité de Trasplantes que esté llevando a cabo la evaluación del candidato.

b) Falta de adherencia que compromete la salud y los resultados del trasplante a pesar de la edu- 
cación y asesoramiento encaminados a corregir la no adherencia.

c) Enfermedad maligna activa, excepto para aquellos con cánceres de bajo grado, indolentes y curables antes del trasplante.

d) Enfermedad pulmonar obstructiva o restrictiva avanzada e irreversible.

e) Enfermedad neurodegenerativa progresiva.

f) Heridas (úlceras) con infección activa en las extremidades hasta su resolución completa.

g) Mieloma múltiple con nefropatía por cilindros (proteínas de Bence Jones), excepto para aquéllos que reciben tratamiento potencialmente curativo o se encuentran en remisión estable.

h) Enfermedad de cadenas ligeras, enfermedad de cadenas pesadas o con presencia de depósito de ambas (ligeras y pesadas).

i) Amiloidosis sistémica con depósitos cardiacos. (La posible evaluación de candidatura a trasplante combinado corazón-riñón no es el propósito de este consenso).

j) Aun en el caso de pacientes con una historia de haber sufrido una enfermedad maligna, si ésta no está activa, deberán ser referidos para su evaluación como posibles CTR. Será la responsabilidad del Comité de Trasplantes el definir si existe o no una contraindicación para que se lleve a cabo un trasplante en dicho paciente.

2. La(s) razón(es) por la(s) cual(es) un paciente no es considerado candidato a ser evaluado para trasplante renal deberá(n) quedar consignada(s) en el expediente clínico.

3. Es indispensable garantizar que todo paciente receptor de trasplante recibirá los medicamentos inmunosupresores de manera permanente e indefinida.

4. Es deseable:

a) Que el paciente sea informado sobre la opción de tener una segunda opinión en otro centro de trasplantes o por otro grupo médico, en caso de que el centro evaluador haya declinado su candidatura a trasplante renal.

b) Contar con un grupo multidisciplinario que incluya como mínimo un clínico de trasplantes (de preferencia nefrólogo) y un cirujano de trasplantes para evaluar y decidir la idoneidad del paciente para trasplante.

c) Únicamente aprobar a pacientes para trasplante renal que tengan una supervivencia estimada aceptable de acuerdo con las prácticas locales.
5. Referencia y contrarreferencia:

a) Para todos los receptores de trasplante sería ideal que el seguimiento postrasplante ocurra en la misma institución donde se llevó a cabo el procedimiento.

b) De no ser posible lo anterior, debido a las características y disposiciones de la institución de salud, deberá por lo menos garantizarse la preparación en trasplantes del grupo médico que otorgará el seguimiento al paciente.

c) Deberá quedar vigente el mecanismo para el envío del paciente a la institución primaria en la cual se llevó a cabo el trasplante en caso de requerirse algún procedimiento diagnóstico, tratamiento o evaluación médica que no pueda ser otorgado en la institución en la cual se lleva a cabo el seguimiento.

En la actualidad, no existe duda alguna de que el trasplante es la mejor alternativa terapéutica para la pérdida irreversible de la función renal. Los beneficios ampliamente demostrados del trasplante renal son la calidad y número de años de vida a un costo significativamente menor comparado con cualquiera de las modalidades dialíticas. ${ }^{1-6}$ Es por esto que es indispensable que todos los pacientes con insuficiencia renal avanzada sean informados de las opciones de tratamiento de reemplazo de la función con suficiente antelación, incluyendo la opción de trasplante renal. Esta información también debe incluir la opción de manejo conservador en casos de esperanza de vida limitada por la existencia de comorbilidades avanzadas. De esta forma, los pacientes con TFGe $<30 \mathrm{~mL} / \mathrm{min} / 1.73$ $\mathrm{m}^{2}$ deben ser referidos al nefrólogo con el propósito de conocer la posibilidad de trasplante renal anticipado a diálisis. Es evidente que ello dependerá de diversos factores, incluyendo el que no exista una condición médica o patología que contraindique la referencia para evaluación a trasplante, así como de la disponibilidad de contar con un potencial donante renal vivo dispuesto a satisfacer la necesidad del injerto para el potencial receptor.

En México $70 \%$ de los trasplantes renales que se realizan proceden de donantes vivos, en su mayoría relacionados por consanguinidad. A su vez, $70 \%$ de los receptores se encuentran entre los 20 y 44 años de edad; otro $21 \%$ entre 45 y 64 años, ${ }^{7}$ de tal suerte que la referencia oportuna, particularmente de estos pacientes, permite llevar a cabo todas las evaluaciones del donante y del receptor con la antelación suficiente para programar un tras- 
plante anticipado, procedimiento que confiere los mejores resultados.

El tiempo que pudiera tomar el estudio es variable y depende de la institución de salud que tenga a cargo el cuidado del paciente, debiendo prevalecer el propósito de tener completamente concluido el estudio para lograr el trasplante prediálisis. El momento óptimo para llevar a cabo el trasplante anticipado a diálisis deberá ser individualizado y dependerá de los síntomas del paciente y de la TFGe.

Hemos enfatizado en esta sección al trasplante renal de donante vivo porque este consenso trata precisamente del estudio de la pareja donante vivo-receptor. Sin embargo, los pacientes referidos de manera oportuna al nefrólogo para evaluación para trasplante y que no cuenten con un donante vivo potencial podrán ser inscritos en lista de espera, incluso del periodo predialítico. En estos casos es preferible que la evaluación esté concluida antes de la inscripción a la lista de espera para trasplante de donante fallecido. Ello aplica también para los pacientes que ya se encuentran en terapia dialítica, con falla irreversible de la función renal, quienes deberán ser evaluados para trasplante renal, y de no existir una condición médica o patología que contraindique el trasplante, se tendrá que evaluar la opción de trasplante de donante vivo o ser inscritos en lista de espera.

La referencia y contrarreferencia es un procedimiento médico-administrativo entre unidades operativas de los tres niveles de atención para facilitar el envío-recepción-regreso de pacientes, con el propósito de brindar atención médica oportuna e integral de la salud; además, opera prácticamente en todas las instituciones que componen el Sistema Nacional de Salud. Esta modalidad debe funcionar en forma altamente competente, de tal forma que la referencia de los pacientes con ERC y TFGe $<30$ $\mathrm{mL} / \mathrm{min} / 1.73 \mathrm{~m}^{2}$ ocurriera de manera oportuna a los servicios de nefrología, de acuerdo con lo señalado anteriormente.

Todos los aspectos que competen a la lista de espera nacional para trasplante renal de donante fallecido, las oportunidades de recibir este beneficio en nuestro país, la temporalidad de la reevaluación de diversos estudios durante la espera, serán tratados en un consenso independiente que se llevará a cabo próximamente.

\section{REFERENCIAS}

1. Lentine KL, Kasiske BL, Levey AS, Adams PL, Alberú J, Bakr $\mathrm{MA}$ et al. KDIGO clinical practice guideline on the evaluation and care of living kidney donors. Transplantation. 2017; 101 (8S): S1-S109.

2. Laupacis A, Keown P, Pus N, Krueger H, Ferguson B, Wong C et al. A study of the quality of life and cost-utility of renal transplantation. Kidney Int. 1996; 50: 235-242.

3. Tonelli M, Wiebe N, Knoll G, Bello A, Browne S, Jadhav D et al. Systematic review: kidney transplantation compared with dialysis in clinically relevant outcomes. Am J Transplant. 2011; 11: 2093-2109.

4. Haller M, Gutjahr G, Kramar R, Harnoncourt F, Oberbauer R. Cost-effectiveness analysis of renal replacement therapy in Austria. Nephrol Dial Transplant. 2011; 26: 2988-2995.

5. Wong G, Howard K, Chapman JR, Chadban S, Cross N, Tong A, et al. Comparative survival and economic benefits of deceased donor kidney transplantation and dialysis in people with varying ages and comorbidities. PLoS One. 2012; 7: e29591.

6. Klarenbach SW, Tonelli M, Chui B, Manns BJ. Economic evaluation of dialysis therapies. Nat Rev Nephrol. 2014; 10: 644652.

7. Centro Nacional de Trasplantes. Disponible en: cenatra.www. salud.org.gob.mx

Correspondencia:

Dr. Jacobo Kelber Berger

E-mail: jkelber@me.com 